\title{
Clinical Trial Protocol Deviation Document
}

National Cancer Institute

\section{Source}

National Cancer Institute. Clinical Trial Protocol Deviation Document. NCI Thesaurus.

Code C115664.

Records that detail any non-compliance or deviations from a clinical study's protocol. 